\title{
Social media: new links for Indigenous health
}

\section{Public health journalist Melissa Sweet highlights successes that have resulted from innovative use of social media}

round the world, social media is a disrupting and transforming force, bringing new opportunities for innovation and participation. ${ }^{1}$ In the United States, the Centers for Disease Control and Prevention have developed resources to provide guidance on using social media in health communication. ${ }^{2}$ In the United Kingdom, the NHS Institute for Innovation and Improvement encouraged its staff to explore the potential of using social media to transform care and staff engagement. ${ }^{3}$

In Australia, the Indigenous health sector has been at the forefront of innovative use of social media for advocacy, public health promotion and community development. Two striking examples are the Lowitja Institute's nuanced explanation of knowledge exchange from Indigenous perspectives ${ }^{4}$ and the Healing Foundation's engaging explanation of the impact of colonisation on Indigenous health. ${ }^{5}$

The National Aboriginal Community Controlled Health Organisation (NACCHO) was an early adopter of social media, and finds it a valuable advocacy tool, according to its Chair, Justin Mohamed. It distributes daily Aboriginal health news alerts via social media. Mohamed says downloads of NACCHO's policy submissions have increased since they have been promoted on Twitter and other online channels.

The popularity of user-generated content - a hallmark of social media - is being harnessed in new tobacco control programs. These include the No Smokes campaign from the Menzies School of Health Research and the Rewrite Your Story initiative by Nunkuwarrin Yunti (a communitycontrolled service). In New South Wales, the Aboriginal Health and Medical Research Council uses Facebook to promote sexual health and smoking cessation.

While the digital divide is thought to be an issue relevant to remote and hard-to-reach communities, ${ }^{6}$ social media has been successfully used in the Torres Strait Islands to connect young people with a public health initiative in sexual health - the Kasa Por Yarn ("just for a chat") campaign, funded by Queensland Health. Unpublished data show that Facebook, YouTube and text messaging were effective in reaching the target audience of 15-24-year-olds (Heather Robertson, Senior Network Project Officer, Cairns Public Health Unit, Queensland Health, personal communication). Patricia Fagan, a public health physician who oversaw the campaign, says that social media helped increase its reach. The campaign was using tools with appeal to young people, and, importantly, "it didn't feel like health, it felt like socialising". Heather Robertson, the project leader, says engaging local writers, musicians and actors in developing campaign messages and social media content was also important.

Social media has also been used to increase engagement with the Heuristic Interactive Technology network (HITnet),

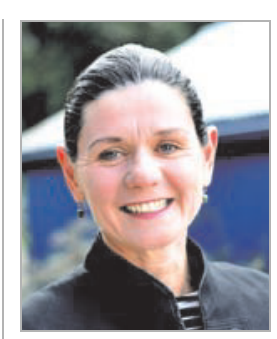

Melissa A Sweet MA(SciTechStud), BA, Adjunct Senior Lecturer ${ }^{2}$

IUniversity of Canberra, Canberra, ACT.

2 Sydney School of Public Health, University of Sydney, Sydney, NSW.

melissa@sweet communication.com.au

doi: 10.5694/mjal3.10429

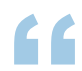

the Indigenous health sector has been at the forefront of innovative use of social media

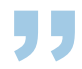
PhD Candidate, and

which provides touch-screen kiosks in Indigenous communities and in prisons. The kiosks embed health messages in culturally based digital storytelling. Helen Travers, Director of Creative Production and Marketing for HITnet, says this has brought wider health benefits, by developing the content-creation skills of communities. "The exciting thing for health promotion is that this kind of work is increasing digital literacy and digital inclusion", she says.

Social media's facilitation of citizen-generated movements is exemplified by the @IndigenousX Twitter account, where a different Indigenous person tweets every week, enabling many health-related discussions.

Innovation in service development is also being informed by the anti-hierarchical, decentralised nature of social media. The Young and Well Cooperative Research Centre is developing virtual mental health resources for Indigenous youth in remote communities. The centre's Chief Executive Officer, Jane Burns, envisages that these will resemble a social network more than a health care intervention, and will link young people and their health care providers with online collection of data about sleep, weight, physical activity and related measures. Burns says, "It really is ... creating a new mental health service, a new way of doing things that empowers the individual, rather than being that top-down service delivery approach".

However, barriers to wider use of social media exist. Burns says that upskilling health professionals is critical. Kishan Kariippanon, a former paediatric physician studying social media and mobile phone use among youth in the Yirrkala community in Arnhem Land, says health professionals need support and encouragement to engage more creatively with technological innovations. He would like to see regular "hackathons" to bring together programmers, health professionals, innovators and community members to encourage "out of the box" thinking.

Competing interests: In 2012, I presented on media developments, including social media, at Aboriginal Health and Medical Research Council and Lowitja Institute conferences; my travel and accommodation expenses were covered. In 2010, I presented on media and social media to the Australian Indigenous Doctors' Association; I was paid a fee and my travel expenses were covered.

Provenance: Commissioned; externally peer reviewed.

1 World Economic Forum. Global Agenda Council on Social Media 2012-2013. http://www.weforum.org/ content/global-agenda-council-social-media-2012 (accessed Feb 2013).

2 Centers for Disease Control and Prevention. The health communicator's social media toolkit. 2011. http://www.cdc.gov/healthcommunication (accessed Feb 2013).

3 NHS Institute for Innovation and Improvement. Transforming care and staff engagement through the power of social media - a series of online seminars for the NHS. http://t.twi.to/qdd-/seg5u (accessed Feb 2013).

4 Lowitja Institute. What is knowledge exchange [video]? http://www.youtube.com/watch?v=PA8RVGNXokc (accessed Feb 2013).

5 Healing Foundation. The story of the Healing Foundation [video]. http://www.youtube.com/watch?v= zDN7R6qRpUg (accessed Feb 2013).

6 Newman L, Biedrzycki K, Baum F. Digital technology use among disadvantaged Australians: implications for equitable consumer participation in digitally-mediated communication and information exchange with health services. Aust Health Rev 2012; 36: 125-129. 